\title{
Vasculitis ANCA positiva inducida por Propiltiouracilo. Reporte de caso
}

\author{
Propylthiouracil induced ANCA positive vasculitis. A case report \\ Marco Antonio Soto Fonseca1,a, Katherine Fernanda Medina Ramírez²,b, Karen Sánchez Barjún 2,c
}

\section{RESUMEN}

La vasculitis asociada a propiltiouracilo (PTU) y ANCA es una enfermedad rara con una incidencia de 0,47-0,71 casos por cada 10000 pacientes. Afecta principalmente a los vasos de menor calibre. Piel, riñones y pulmones son los más afectados. El diagnóstico requiere alta sospecha clínica y se apoya en estudios histopatológicos de las lesiones en piel y serología positiva para ANCA. La suspensión del medicamento suele bastar como manejo de la enfermedad. Mujer de 45 años de edad, con historia de consumo de PTU durante 2 años, desde su diagnóstico de hipertiroidismo; presentando placas purpúricas dolorosas en ambos miembros inferiores.

PALABRAS CLAVE: Propiltiouracilo, anticuerpos anticitoplasma de neutrófilos, vasculitis. (Fuente: DeCS BIREME).

\section{SUMMARY}

ANCA vasculitis associated to propylthiouracil (PTU) is a rare condition with an incidence of $0.47-0.71$ cases per 100,000 patients. It affects mainly minor caliber blood vessels. The skin, kidneys and lungs are the organs most affected. To make the diagnosis it is necessary to have a high index of suspicion and rely on histopathologic findings of skin lesions plus a positive ANCA test. Stopping the inducing drug is usually necessary to manage this condition. We report the case of a 45-year-old woman who consumed PTU for two years for the treatment of hyperthyroidism presenting with painful purpuric plaques in the lower limbs.

KEYWORDS: Propylthiouracil, antineutrophil cytoplasmic antibodies, vasculitis. (Source: MeSH NLM).

\section{INTRODUCCIÓN}

La vasculitis es un grupo heterogéneo de enfermedades de etiología variable, entre ellos, trastornos autoinmunes, infecciones, drogas y neoplasias, aunque también puede ser idiopática. Los fármacos asociados a síndromes vasculíticos van en aumento. Entre las drogas causantes de vasculitis se encuentran antibióticos beta-lactámicos, eritromicina, clindamicina, vancomicina, sulfonamidas, y otras como, furosemida, alopurinol, antiinflamatorios no esteroideos (AINE), amiodarona, tiazidas, fenitoína, ácido valproico, beta-bloqueadores, metformina, warfarina, anticuerpos monoclonales usados en el tratamiento de enfermedades autoinmunes y fármacos anti tiroideos ${ }^{(1,2,3)}$.

\footnotetext{
Hospital Escuela Universitario, Universidad Nacional Autónoma de Honduras. Tegucigalpa, Honduras.

Universidad Nacional Autónoma de Honduras. Tegucigalpa, Honduras.

Médico residente de segundo año en Postgrado de Medicina Interna;

Médico General;

Médico especialista en Medicina Interna.
} 
A parte del daño a la función hepática conocido por el tratamiento con fármacos anti tiroideos como el propiltiouracilo (PTU), otros tres efectos adversos importantes son: afectación a los sistemas linfático y sanguíneo, enfermedades de la piel y tejido celular subcutáneo y reacciones sistémicas parciales en respuesta al medicamento. Manifestaciones específicas son agranulocitosis, hipotiroidismo, rash y urticaria, fiebre, escalofríos, leucopenia y dolor articular ${ }^{(4)}$.

La mayoría de los estudios disponibles de vasculitis inducida por consumo de propiltiouracilo consiste de reportes de casos o series pequeñas. El primer caso reportado fue en 1992 por Stankus et al. ${ }^{(5)}$, al año siguiente, Dolman et al. ${ }^{(6)}$, reportaron seis nuevos casos de la enfermedad.
No existe en Honduras la opción de tratamiento con yodo radioactivo para el manejo de la patología hipertiroidea. La única terapia definitiva disponible es la tiroidectomía hasta el momento. Debido a la demora quirúrgica en el sistema público de salud, los pacientes se ven expuestos al tratamiento prolongado con PTU, el cual se ve relacionado a efectos adversos como vasculitis y agranulocitosis.

\section{PRESENTACIÓN DE CASO}

Mujer de 45 años de edad, procedente de El Paraíso, Honduras, ocupación costurera. Acudió a emergencia del Hospital Escuela Universitario de Tegucigalpa por presentar fiebre, de tres días de evolución, no cuantificada, subjetivamente alta, sin predominio

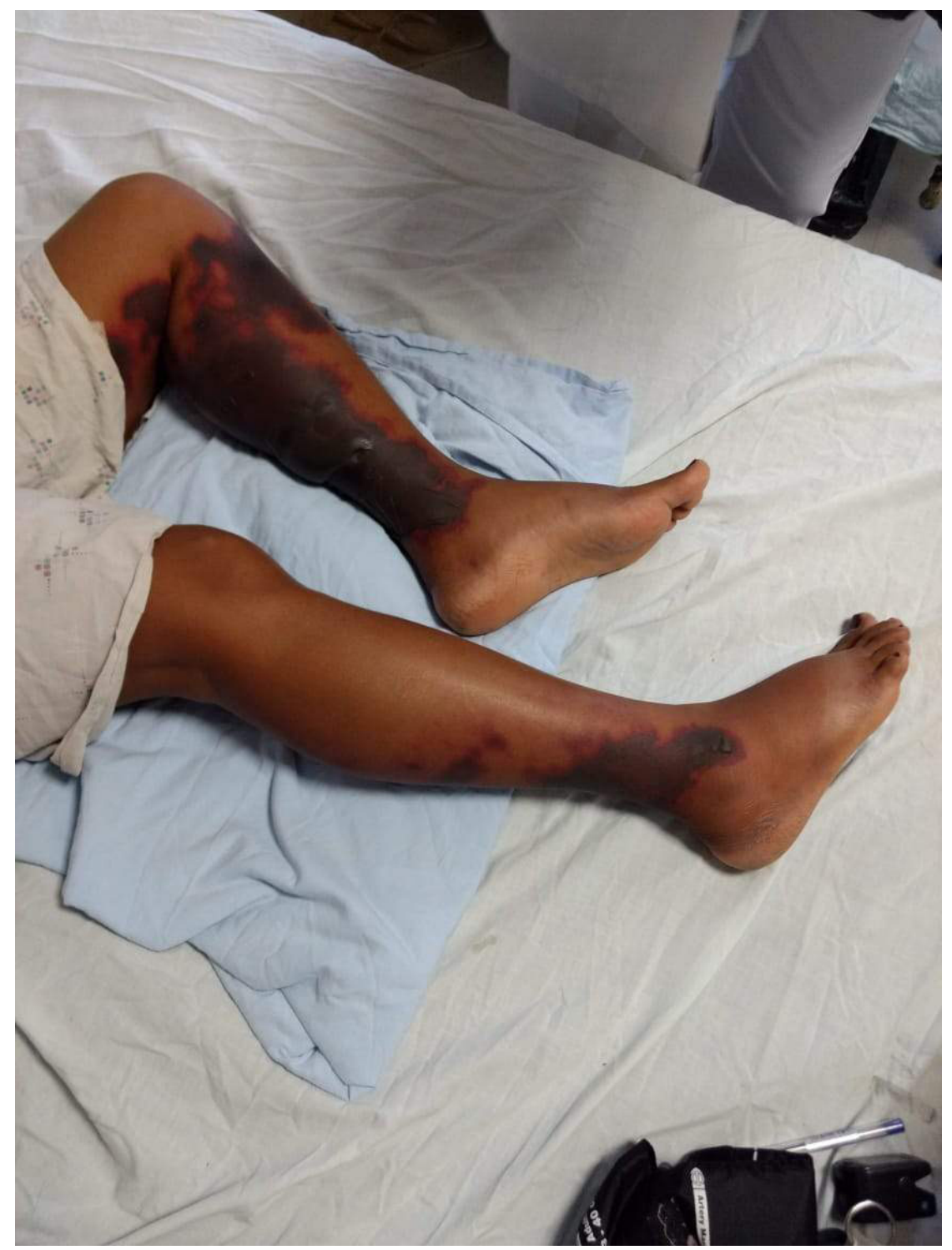

Figura 1. Lesiones violáceas, tipo placas en ambos miembros inferiores. 
de horario, malestar general y dolor localizado en miembros inferiores de tipo urente que se acompañaba de lesiones violáceas, tipo placas en ambos miembros inferiores (figura 1). Tenía diagnóstico de hipertiroidismo desde hace dos años, manejado en Hospital General San Felipe, con propiltiouracilo (PTU) 450mg vía oral cada día y propranolol $40 \mathrm{mg}$ vía oral cada día; la última cita médica había sido hace más de 1 año. Historia ginecobstétrica: G: 2 P: 2 , ciclos regulares.

$\mathrm{Al}$ ingreso, la presión arterial: 130/80 mm Hg, frecuencia cardiaca: 81 latidos por minuto; pulso: 81 pulsaciones por minuto; frecuencia respiratoria: 17 respiraciones por minuto; temperatura: $37^{\circ} \mathrm{C}$. Al examen físico: Glasgow $15 / 15$, no oftalmopatía; bocio palpable, no doloroso, no nodular. No adenopatías cervicales. Edema de miembros inferiores bilateral, distal hasta la rodilla, 2+ en miembro inferior izquierdo $\mathrm{y}+$ en miembro inferior derecho sin calor ni rubor, acompañado de placas purpúricas extensas, polimorfas, confluentes en muslos y piernas; pulsos presentes, llenado capilar $<2$ seg. Ingresó por el servicio de medicina interna. Al ingreso se inició tratamiento con prednisona $60 \mathrm{mg}$ vía oral cada/día, propranolol $40 \mathrm{mg}$ vía oral $\mathrm{c} / 8 \mathrm{~h}$, además de diclofenaco $50 \mathrm{mg}$ intravenoso $\mathrm{c} / 12 \mathrm{~h}$, tramadol $50 \mathrm{mg}$ subcutáneos $\mathrm{c} / 8$ h y metoclopramida $10 \mathrm{mg}$. Así mismo se omitió PTU por su asociación a efectos secundarios relacionados a su uso prolongado como agranulocitosis y vasculitis.
Los exámenes de laboratorio mostraron hemograma hemoglobina: $13,6 \mathrm{~g} / \mathrm{dl}$ hematocrito: $36,8 \%$ leucocitos: 4,340; neutrófilos: $59,0 \%$ linfocitos: $22,4 \%$. Glicemia $94 \mathrm{mg} / \mathrm{dl}$, nitrógeno ureico sanguíneo: $12 \mathrm{mg} / \mathrm{dl}$, creatinina: $0,78 \mathrm{mg} / \mathrm{dl}$, sodio: $133 \mathrm{mmol} / \mathrm{l}$, potasio: 3,4 $\mathrm{mmol} / \mathrm{l}$, aspartato amino transferasa: $26 \mathrm{U} / \mathrm{l}$, alanina amino transferasa: $32 \mathrm{U} / 1$. El examen de orina evidenció color amarillo, aspecto ligeramente turbio, sangre $1+$, proteínas $1+$, nitritos negativo; hematíes: 10-12 xc, leucocitos: 8-9 xc, cilindros: 1-2, abundantes fosfatos de calcio. No se realizó proteinuria de $24 \mathrm{~h}$.

Las pruebas de función tiroidea mostraron: TSH $0,378 \mu \mathrm{IU} / \mathrm{ml}(0,4-4 \mu \mathrm{IU} / \mathrm{ml})$; T4 libre: $1,69 \mathrm{ng} / \mathrm{dl}$ $(0,89-1,76 \mathrm{ng} / \mathrm{dl})$. Velocidad de sedimentación globular $82 \mathrm{~mm} / \mathrm{h}$; proteína $\mathrm{C}$ reactiva $96 \mathrm{mg} / \mathrm{dl}$, anticuerpos antinucleares (ANA) $0,347 \mathrm{U} / \mathrm{ml}$ (Valor Normal $<0,9$ ); anticuerpos anticitoplasma de neutrófilos mieloperoxidasa (ANCA MPO) 1,609 U/ml (Positivo $>1,1)$; anticuerpos anticitoplasna de neutrófilos proteinasa 3 (ANCA PR3) 3,243 U/ml (Positivo >1,1), $\mathrm{C}_{3}$ no se determinó, $\mathrm{C}_{4} 18,63 \mathrm{mg} / \mathrm{dl}$ (Valor normal 9-36).

El ultrasonido de miembros inferiores no mostró hallazgos anormales. Así mismo, la radiografía de tórax y ultrasonido renal y de vías urinarias, fueron normales. La biopsia de las lesiones mostró vasculitis leucocitoclástica de pequeños vasos.

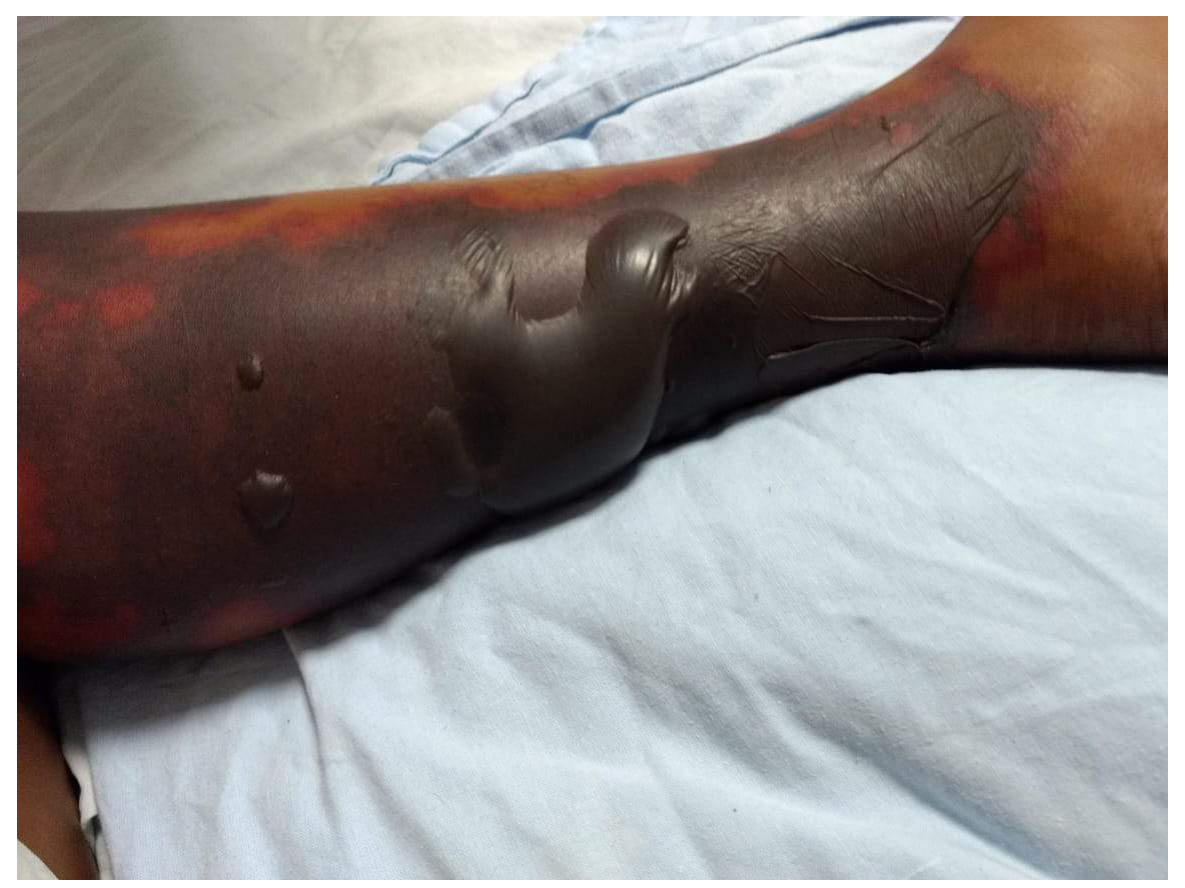

Figura 2. Bulas en miembros inferiores. 
Posteriormente, la paciente presentó bulas en miembros inferiores, acompañadas de secreción purulenta y fétida por lo que recibió tratamiento antibiótico con clindamicina $600 \mathrm{mg}$ intravenoso c/8h, por 7 días (figura 2). Permaneció hospitalizada en el servicio de medicina interna, al décimo día intrahospitalario se realizó tiroidectomía total como tratamiento definitivo de su hipertiroidismo y limpieza quirúrgica de miembros inferiores afectados; no hubo complicaciones en el post operatorio, la evolución fue adecuada. Salió de alta al tercer día post operada con tratamiento ambulatorio con levotiroxina $100 \mathrm{mg}$ vía oral cada día.

\section{DISCUSIÓN}

La vasculitis inducida por drogas se ha definido como cualquier caso de vasculitis inflamatoria en el cual se ha establecido una droga específica como agente causal de la enfermedad luego de excluir otros causantes. La vasculitis de pequeños vasos es la que se asocia con mayor frecuencia a vasculitis inducida por drogas. En el 2012, se revisó el Consenso de la Conferencia de Chapel Hill de 1994, agregando una nueva categoría de "vasculitis asociada a probable etiología", ésta incluye dos formas de vasculitis inducida por drogas: una variante asociada a inmunocomplejo y la otra asociada a ANCA. Así mismo, definieron la variante asociada a ANCA como una vasculitis necrozante, con poco o ningún depósito de inmuno-complejo, afectando predominantemente vasos de pequeño calibre en asociación con mieloperoxidasa (MPO)-ANCA y proteinasa-3 (PR3)-ANCA y enfatizaron la importancia de indicar la especificidad de ANCA debido a que MPO-ANCA y PR3-ANCA sugieren diferencias entre la enfermedad $(1,7)$.

La patogénesis de la vasculitis inducida por drogas no es clara. Se cree multifactorial y que en el caso de PTU, la MPO liberada desde neutrófilos activados puede convertir al PTU (y a la hidralazina) en metabolitos inmunogénicos que inducen la producción de ANCA. La incidencia de la vasculitis asociada al tratamiento anti tiroideo es de 0,53-0,79 casos por cada 10000 pacientes con enfermedad de Graves. Estudios sugieren mayor relación entre PTU y la vasculitis asociada a ANCA y que el predominio de MPO-ANCA sobre PR3-ANCA tiene mejor pronóstico $^{(1,8)}$.

La vasculitis asociada a PTU y ANCA es una enfermedad rara con una incidencia de $0,47-0,71$ casos por cada 10000 pacientes y prevalece en mujeres (probablemente por el predomino de la enfermedad de Graves en este sexo) sobre hombres con 8,8:1, con un rango de edad entre 19-64 años. El tiempo entre el inicio de tratamiento con PTU hasta el desarrollo de vasculitis varía ampliamente desde una semana hasta 13 años (media 36 meses), asociado a la ingesta de $50-450 \mathrm{mg}$ del medicamento ${ }^{(8,9,10,11,12)}$, estos datos concuerdan con los de nuestra paciente, femenino de 45 años de edad, con dos años de tratamiento de PTU a una dosis de $450 \mathrm{mg}$ /día.

La clínica puede variar, desde un cuadro inespecífico con malestar general, fiebre, mialgias y artralgias, hasta otros que pueden poner en riesgo la vida del paciente debido a que la inflamación de pequeños vasos puede ocurrir en todos los órganos. La piel, los riñones y pulmones son los órganos más afectados; sistema nervioso central, oído e hígado son otros afectados con menor frecuencia. El daño pulmonar se manifiesta con tos, expectoración, hemoptisis y hemorragia alveolar difusa en los casos graves. Hematuria y proteinuria son los datos más frecuentes encontrados en casos de vasculitis renal. La afectación cutánea reportada en estos casos consiste de lesiones acrales y placas purpúricas que pueden progresar hacia vesículas y bulas con necrosis central y pérdida de tejido secundarios; las cuales concuerdan con las lesiones en piel encontradas al examen físico de la paciente de nuestro caso. Cara, orejas y mamas también pueden presentar lesiones de piel ${ }^{(1,10,11,12)}$.

Los estudios de laboratorio comúnmente reportan leucopenia y agranulocitosis como en nuestro caso y además, anemia, trombocitopenia. Elevación de las concentraciones de urea, creatinina y transaminasas, hipoalbuminemia, tiempos de coagulación prolongados, aumento del VES y PCR y serología positiva para ANCA; $15-64 \%$ de los pacientes con tratamiento con PTU presentan serología positiva para ANCA. La biopsia de piel es una herramienta útil para el diagnóstico. Habitualmente reporta vasculitis leucocitoclástica de vasos superficiales y profundos, oclusión de vasos sanguíneos con trombos de fibrina y necrosis. Los hallazgos histopatológicos y la serología positiva para ANCA, específicamente MPO-ANCA o PR3-ANCA respaldan el diagnóstico altamente sugestivo por clínica. Según la literatura encontrada, PTU induce con mayor frecuencia MPOANCA y es la variante asociada a mejor pronóstico; sin embargo, en la paciente en cuestión, se encontró mayor elevación de PR3-ANCA que MPO-ANCA, aunque ambos estaban elevados. Biopsias de pulmón y 
riñón podrían ser de utilidad. Hematuria y proteinuria, comunes indicativos de daño renal también estuvieron presente en el caso, sin otro indicativo aparte de daño de órganos. El diagnóstico diferencial de la vasculitis secundaria a fármacos incluye infecciones, patologías malignas y vasculitis idiopáticas ${ }^{(1,8,11,13)}$.

Para el tratamiento, la sola suspensión del PTU suele bastar para el cese de la clínica. La inmunomodulación es la intervención más frecuente. Los medicamentos más utilizados son prednisona (como en este caso), prednisolona, ciclofosfamida y azatioprina. Luego de este, los títulos de ANCA decaen en algunos pacientes durante meses, aunque en otros, este permanece elevado, más no asociado a vasculitis ${ }^{(10)}$.

\section{Declaración de conflictos de interés:}

Los autores declaran no tener conflictos de interés.

\section{Contribución de autoría:}

MASF; KFMR; KSB: Participaron en la redacción del reporte y en la aprobación de la versión final a ser publicada.

\section{Correspondencia:}

Marco Antonio Soto Fonseca

Correo electrónico:maco_s2@hotmail.com

\section{REFERENCIAS BIBLIOGRÁFICAS}

1. Grau RG. Drug induced vasculitis: new insights and a changing lineup of suspects. Curr Rheumatol Rep. 2015; 17:71. DOI: 10.1007/s11926-015-0545-9

2. Baigrie D, Crane JS. Leukocytoclastic Vasculitis (Hypersensitivity Vasculitis). Treasure Island (FL): StatPearls Publishing; 2020. (Citado el 2 de marzo del 2020) Disponible en: https://europepmc.org/ books/NBK482159; jsessionid=C4B6EEFC30ECDA 38B4961420236FC544

3. Hernández-López A, Panigua-Tapia MU, Cortés-Rojo $\mathrm{C}$, Rodríguez-Orozco AR. Vasculitis leucocitoclástica (vasculitis por hipersensibilidad). Med Int Méx. 2019;35(2):251-267. Doi: 10.24245/mim. v35i2.2351

4. Yu W, Wu N, Li L, Wang J, OuYang H, Shen H. Side effects of PTU and MMI in the treatment of hyperthyroidism: a systematic review and metaanalysis. Endocr Pract. 2020; 26(2):207-217. doi:10.4158/EP-2019-0221
5. Stankus J, Johnson N. Propylthiouracil-induced hypersensitivity vasculitis presenting as respiratory failure. CHEST. 1992; 102(5):1595-1596. Doi: 10.1378/chest.102.5.1595

6. Dolman K, Gans R, Vervaat T, et al. Vasculitis and antineutrophil cytoplasmic autoantibodies associated with propylthiouracil therapy. Lancet. 1993; 342:65152.

7. Jennette JC. Overview of the 2012 revised International Chapel Hill Consensus Conference nomenclature of vasculitides. Clin Exp Nephrol. 2013; 17(5):603-606. doi:10.1007/s10157-013-08696

8. Chen M, Gao Y, Guo X, et al. Propylthiouracilinduced antineutrophil cytoplasmic antibodyassociated vasculitis. Nat Rev Nephrol. 2012; 8: 476483. doi:10.1038/nrneph.2012.108

9. Wall AE, Weaver SM, Litt JS, Rae L. PropylthiouracilAssociated Leukocytoclastic Necrotizing Cutaneous Vasculitis: A Case Report and Review of the Literature. J Burn Care Res. 2017; 38(3):e678-e685. doi: 10.1097/BCR.0000000000000464

10. Yang J, Yao LP, Dong MJ, et al. Clinical characteristics and outcomes of propylthiouracil-induced antineutrophil cytoplasmic antibody-associated vasculitis in patients with Graves' disease: A median 38 -month retrospective cohort study from a single institution in China. Thyroid. 2017;27(12):14691474. doi: $10.1089 /$ thy. 2017.0468

11. Criado PR, Grizzo AC, Gaviolli CF, Alavi A. Propylthiouracil-Induced Vasculitis with Antineutrophil Cytoplasmic Antibody. Int J Low Extrem Wounds. 2015; 14(2): 187-191. Doi: $10.1177 / 1534734614549418$

12. Balavoine A-S, Glinoer D, Dubucquoi, Wémeau J-L. Antineutrophil cytoplasmic antibody-positive smallvessell vasculities associated with antithyroid drug therapy: how significant is the clinical problem? Thyroid 2015; 25(12):0-0. Doi: 10.1089/ thy. 2014.0603

13. Bilge NSY, Kasifoglu T, Korkmaz C. PTU-induced ANCA-positi vasculitis: an innocent of life threatening adverse effect? Rheumatol Int. 2013; 33:117-120. Doi: 10.1007/s00296-011-2280-5

Recibido: 06/03/2020

Aceptado: 30/12/2020 